\title{
Rhagovelia species from Nosy Boraha east of Madagascar (Hemiptera: Heteroptera: Veliidae)
}

\author{
Herbert ZETTEL \& Alice LACINY \\ $2^{\text {nd }}$ Zoological Department, Natural History Museum Vienna, Burgring 7, 1010 Vienna, Austria; \\ e-mail: herbert.zettel@nhm-wien.ac.at; alice.laciny@nhm-wien.ac.at
}

\author{
Accepted: \\ $22^{\text {nd }}$ June 2020 \\ Published online: \\ $6^{\text {th }}$ July 2020
}

\begin{abstract}
In the years 1992 and 1993, the Austrian entomologist Michael Madl collected semiaquatic Hemiptera on Nosy Boraha (Île Sainte Marie), a small island near the north-eastern coast of Madagascar. The collected material contains five species of Rhagovelia Mayr, 1865, two of which are new to science. Both Rhagovelia madli sp. nov. and Rhagovelia kalalaoensis sp. nov. belong to the $R$. tesari species group. The other three species reported from the island are R. madari Hoberlandt, 1941, R. reuteri Hoberlandt, 1951, and R. tesari Hoberlandt, 1941.
\end{abstract}

Key words. Hemiptera, Heteroptera, Veliidae, Rhagoveliinae, endemism, islands, new species, taxonomy, Île Sainte Marie, Madagascar

Zoobank: http://zoobank.org/urn:1sid:zoobank.org:pub:7CF8BFF6-034F-475E-9A3A-1FA8AF862824

C 2020 The Authors. This work is licensed under the Creative Commons Attribution-NonCommercial-NoDerivs 3.0 Licence.

\section{Introduction}

Nosy Boraha, also called Île Sainte Marie (S 16 ${ }^{\circ} 52^{\prime}-$ $17^{\circ} 07^{\prime}$, E $49^{\circ} 48^{\prime}-50^{\circ} 02^{\prime}$ ), is a small volcanic island off the east coast of Madagascar; the closest distance between the two islands being only about $7 \mathrm{~km}$. Nosy Boraha covers an area of approximately $220 \mathrm{~km}^{2}$; its highest elevation is about $110 \mathrm{~m}$ a.s.l. The Austrian entomologist Michael Madl visited the island in 1992 and 1993 and collected some material of semiaquatic Hemiptera that he donated to the Natural History Museum Vienna. ZETTEL (2020) has described a new species of Eurymetra Esaki, 1926 (Gerridae) from these samples. This study reports on the specimens of the genus Rhagovelia Mayr, 1865 (Veliidae: Rhagoveliinae).

Riffle bugs of the genus Rhagovelia are common inhabitants of streams and rivers in tropical and subtropical zones. This genus contains approximately 400 described species, and many hitherto undescribed species are known from museum collections. Rhagovelia is well known for a high percentage of island endemics (e.g., LUNDBLAD 1936; ZetTel 1996, 2012; Nieser \& al. 1997; POLHEMUs \& ANDERSEN 2010, 2015), which makes the genus highly interesting for evolutionary and biogeographical studies.

The first riffle bug species from Madagascar were described by HOBERLANDT (1941), which were soon followed by further studies containing descriptions of a few more species (PoISSON 1945, 1948, 1951, 1952; HoBERLANDT 1951). However, the actual species diversity of Madagascan Rhagovelia remained largely unknown over the next decades. Only recently, modern revisions of two species groups were presented by PolHemus \& ANDERSEN (2010, 2015), showing the enormous diversity on this island. All Rhagovelia species occurring on Madagascar (including its small adjacent islands) are endemic, and most of them are confined to certain limited regions of the island.

\section{Material and methods}

A total of 44 dry-mounted specimens from Nosy Boraha from the collection of the Natural History Museum Vienna (NHMW) were studied. All specimens were collected in two streams in the Forêt de Kalalao east of the village of Maromandia (ca. S 16 54.3', E 4953.4', $70 \mathrm{~m}$ a.s.1.) (M. Madl, pers. comm.). For comparison, we also studied paratypes of $R$. madari from the National Museum in Prague (NMPC) and further Rhagovelia specimens from the main island of Madagascar in NHMW.

Insects were examined with a Leica Wild M10 binocular microscope (max. 128 $\times$ magnification); studies on parameres were conducted with an OLYMPUS BX40 compound microscope (max. 400× magnification). Drawings were made with the help of a camera lucida fixed to these 
microscopes. The drawing of Figure 17 was obtained from structures (tergites 7 and 8) glued flat on a card board.

Stacked digital images were taken with a Leica DFC490 camera attached to a Leica Z16 APO zoom macroscope, using Leica Application Suite V3. Images were stacked with ZereneStacker 64-bit, and processed with Adobe Photoshop 7.0.

Measurements are given in millimetres and refer to the maximum length or width of the respective structure, unless stated otherwise. The metafemoral width does not include the spines. If no ranges are given, measurements refer to the holotype.

\section{Treatment of species}

\section{Rhagovelia madli sp. nov.} (Figs 1, 2, 5, 7, 9, 11, 13)

Type material. HoLOTYPE (apterous $\precsim$ ) and PARATYPES (1 apterous $\hat{\text {, }}$, 6 apterous + + ): Madagascar, Nosy Boraha: Forêt de Kalalao, 18.XI.1993, leg. M. Madl (all NHMW).

Description. Male (apterous). Measurements (holotype, paratype). Body length 2.66, $\backslash 2.69$; maximum body width (at metapleura) 1.06, 1.08. Head length $0.36,0.38$, width $0.75,0.77$; minimum eye distance $0.10,0.12$. Pronotum length $0.75,0.73$, width $0.97,0.97$. Lengths of antennomeres (holotype), I 0.53, II 0.36, III 0.42, IV 0.47. Lengths of leg segments (holotype): profemur 0.78 , protibia 0.88 , protarsus $0.01+0.02+0.20$, mesofemur 1.44 , mesotibia 1.19 , mesotarsus $0.07+0.41+0.66$, metafemur 1.09 , metatibia 1.20 , metatarsus $0.03+0.04+0.23$.

Colour (Fig. 1). Trunk chiefly black. Pronotum anteriorly with transverse yellow stripe, medially interrupted by narrow blackish line. Tergite 6 with small yellowish brown spot, tergite 7 with large yellow spot. Sternites 3-6 with narrow brownish or yellowish brown lateral margins. Propleuron, mesopleuron, and all acetabula yellow. Venter bicoloured: mesosternum to sternite 6 black, other parts yellow (segment 8 slightly darker). Antenna black, basal third of antennomere 1 yellow. Legs chiefly black; all coxae, pro- and metatrochanter, basal third of profemur, and base of metafemur yellow; mesotrochanter black, with small yellow patch at base.

Pilosity. Body dorsally with short, grey, appressed pubescence; abdomen additionally with inconspicuous, dispersed, dark grey, subdecumbent, short setae; only head, sides of pronotum, and posterior margin of segment 8 with some long black setae. Protrochanter without conspicuous pilosity. Profemur (Fig. 5) on posterior face with basal row of three short spiny setae; posterior row of flexor side with short stout setae. Other black setae on legs normal, slender, of varying length.

Structures. Jugum not flattened, narrow, with few black spicula posteriorly. Proepisternum anteriorly without black spicula. Pronotum more than twice as long as head, covering mesonotum. Protrochanter (Fig. 5) without tubercle. Profemur (Fig. 5) with distinct concavity on extensor side. Metafemur (Fig. 7) moderately incrassate, ca. 3.5-3.6 times as long as wide, on flexor side with rich dentition: basal row consisting of 12-15 densely set short spines only weakly increasing in length distally, their distances mostly smaller than their length; posterodistal row consisting of 12-14 teeth strongly decreasing in size distally, the first one considerably longer than the second; anterodistal row consisting of 10-12 minute spines. Metatibia (Fig. 7) straight, on flexor side with fine tooth-like structures all over length, with very short apical spine. Pregenital segments of abdomen moderately slender. Tergites relatively narrow; tergites 1-5 matt, 6 with a medial shiny spot, 7 almost entirely shiny (except margins). In the holotype, fifth tergite 2.8 times as wide as long; seventh tergite 1.8 times as long as sixth and 1.0 times as long as wide. Sternites almost unmodified; sternite 7 posteriorly with very shallow semicircular depressed area; hind margin slightly concave in middle.

Genital segments small and weakly modified. Pygophore slender, subovate. Proctiger (Fig. 9) slender, basolateral lobes moderately protruding and posteriorly angled. Paramere (Fig. 11) small, curved, but almost parallel-sided over its length; apex hardly widened and evenly rounded.

Female (apterous). Measurements $(\mathrm{n}=6)$. Body length 2.63-2.94; maximum body width (at metapleura) $1.13-1.20$. Head length $0.36-0.42$, width $0.75-0.81$; minimum eye distance $0.10-0.13$. Pronotum length $0.75-0.83$, width 1.03-1.14.

Colour (Fig. 2) of head, thorax and appendages as in male. Tergite 6 more often without, rarely with, very small yellowish dot; spot on tergite 7 very large, almost filling its entire surface. Laterotergites (2)3-6 with a continuous, posteriorly narrowed, yellow stripe over middle parts. Sternites with broad yellow submarginal stripe near connexiva 3-7; on sternite 7 strongly narrowed and absent from connexival corner.

Pilosity of head and thorax similar to that of male, but strongly reduced on tergites 1-3, completely absent from tergites 4-6; tergite 7 with sparse pubescence and some longer black setae at hind margin; tergite 8 with sparse pubescence medially, but with stripes of comparatively long, black setae at sides. Laterotergites 2-6 with stripes of short, inconspicuous pilosity at lateral margins; laterotergite 7 with long, black, posteriorly directed pilosity all over surface. Proctiger with short pilosity; gonocoxa 1 dorsally with black pilosity, other areas only inconspicuously hirsute. Profemur with 3 setae at base of posterior face and the posterior row of flexor side longer and more slender when compared to male.

Structural characteristics. Head and thorax as in male. Mesofemur flattened. Metafemur more slender than that of male, ca. 4.1-4.4 times as long as wide, on flexor side with distal row consisting of 7-10 teeth. Metatibia without dentition on flexor side. Abdomen (Fig. 2) strongly modified. Connexiva convergent on segment 2-3, strongly convergent on segments 4-5, and subparallel on segments 6-7; sternites 3-7 narrowly visible in dorsal aspect of specimen. Connexiva on segments 4-7 slightly thicker than on segments $2-3$, but without distinct swellings. Tergites 1-3 convex, 4-8 flat. Fifth tergite 1.9 times as wide as long; seventh tergite 1.6 times as long as sixth and 1.2 times as long as wide; tergite 6 without or with small shiny spot 


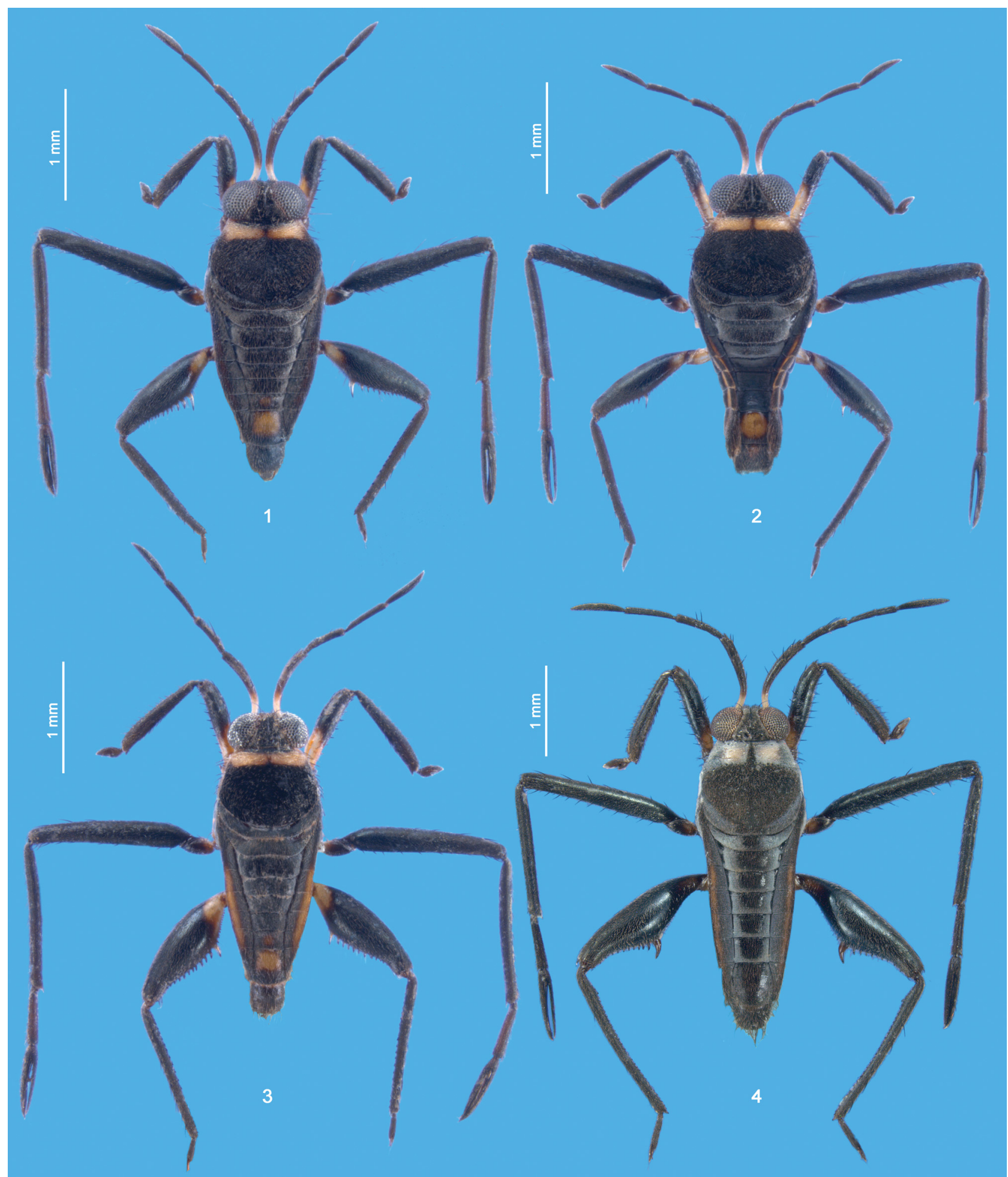

Figs 1-4. 1-2-Rhagovelia madli sp. nov.: 1 - habitus of holotype, apterous male; 2 - paratype, apterous female; 3 - R. kalalaoensis sp. nov., holotype, apterous male; $4-R$. reuteri Hoberlandt, 1951, small apterous male with reduced metatibial tooth.

at middle; tergite 7 almost entirely shiny. Tergite 8 either directed posteriorly or ventroposteriorly. In lateral view (Fig. 13) posterior corner of sternite 7 blunt; ventral outline of gonocoxa 1 straight.

\section{Macropterous morphs. Unknown.}

Comparative notes. Rhagovelia madli sp. nov. is a member of the $R$. tesari group. Within this group it belongs to an assemblage of species (the $R$. ambra subgroup) characterized by spiny setae on the profemora of males (Fig. 5) and the flattened mesofemora of females (PoLHEMUS \& ANDERSEN 2015: key couplet 4). An approximate identification of the new species by the key of PoLHEMUS \& ANDERSEN 2015) already fails in couplet 5, because the characters are contradictory (yellow pronotal spots separated by a narrow black line, but ventral parts of thorax and abdomen partly yellow). Moreover, R. madli sp. nov. 


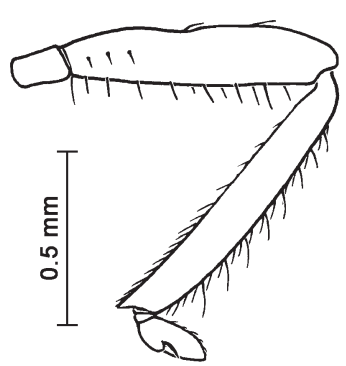

5

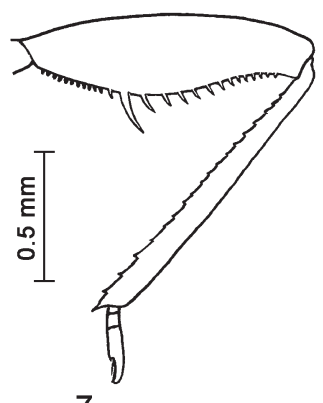

7
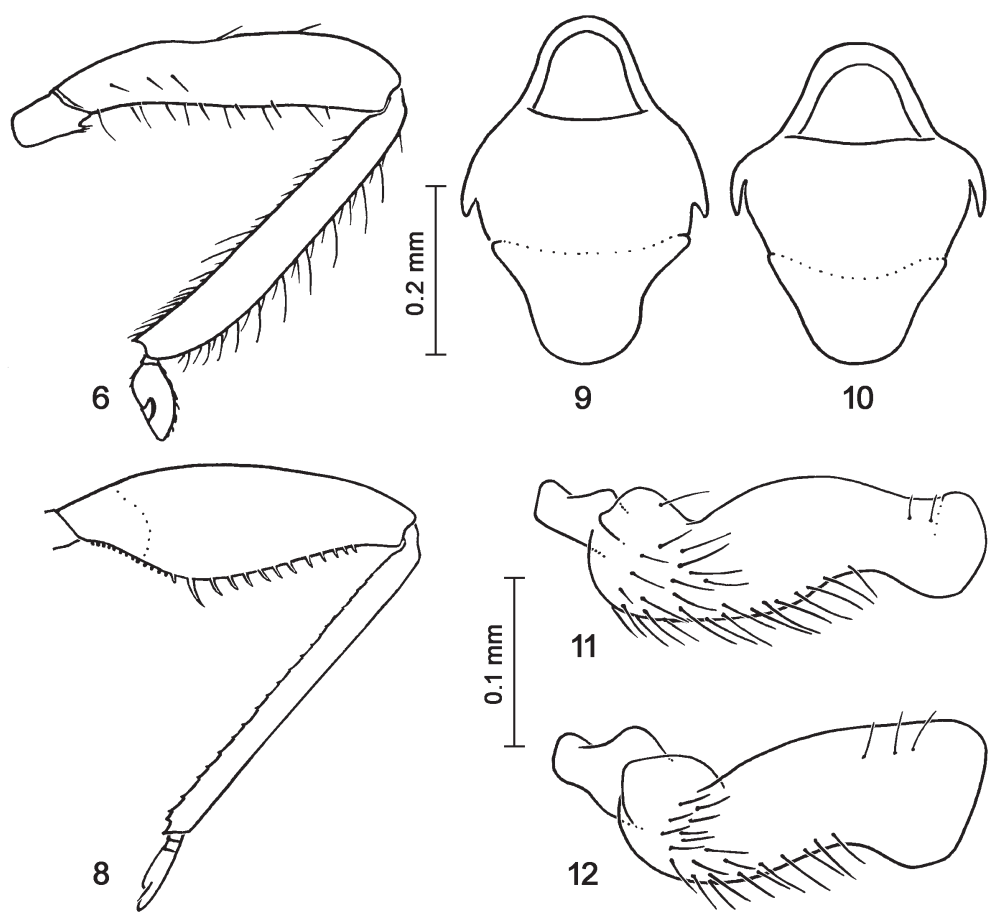

Figs 5-12. Characteristics of males: 5-6 - right foreleg: 5 - Rhagovelia madli sp. nov., $6-R$. kalalaoensis sp. nov.; 7-8 - right hind leg: 7 - R. madli sp. nov. $8-R$. kalalaoensis sp. nov.; 9-10 - pygophore, dorsal view: 9 - $R$. madli sp. nov. $10-R$. kalalaoensis sp. nov.; 11-12 - left paramere, lateral view: $11-R$. madli sp. nov. 12 - R. kalalaoensis sp. nov. Pilosity in Figs 5-6 partly, in Figs 7-10 completely omitted.

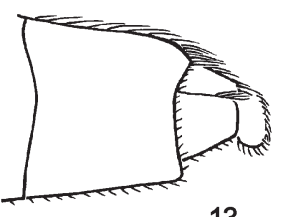

13
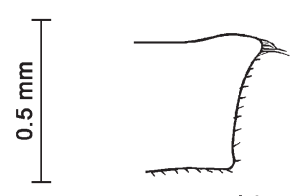

$14 \quad 17$

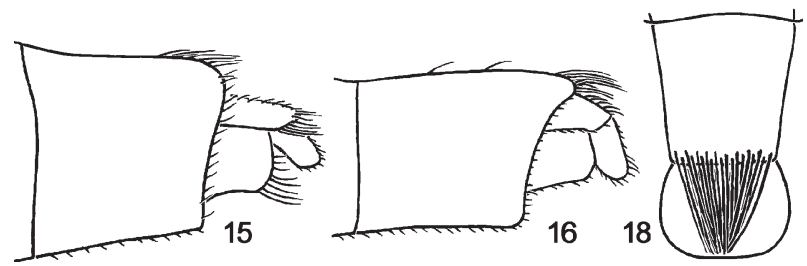

Figs 13-18. Characteristics of females: 13-16-apex of abdomen, lateral view: 13 - Rhagovelia madli sp. nov., $14-R$. kalalaoensis sp. nov., $15-$ R. ambra Polhemus \& Andersen, 2015, $16-R$. aquacola Polhemus \& Andersen, 2015; 17-18 - tergites 7 and 8, dorsal view: $17-R$. kalalaoensis sp. nov., $18-R$. aquacola; pilosity partly omitted.

is distinctly smaller than any previously described species of the R. ambra subgroup.

Based on the structure of the female's abdomen, $R$. madli sp. nov. appears closely related to $R$. ambra Polhemus \& Andersen, 2015, a species endemic to the northernmost region of Madagascar. However, there are several characters separating these two species. For comparison, we used an apterous female of $R$. ambra from the type area, and the original description for the differences in males. In colouration $R$. madli sp. nov. (Figs 1,2) differs from R. ambra by having the yellow pronotal spots separated by a black line (vs. confluent), and by sternites $2-6$ being black except for the connexival margins (vs. yellow except for a black lateral stripe). Differences in apterous females are conspicuous: in $R$. madli sp. nov. the connexiva are almost parallel-sided over segments 6 and 7 in dorsal view (Fig. 7; vs. distinctly convex in $R$. ambra), the laterotergites 7 bear long pilosity all over their surface (vs. long pilosity only posteriorly present in $R$. ambra), the posterolateral connexival angle is bluntly angular in lateral aspect (vs. broadly rounded in $R$. ambra; comp. Figs 13 and 15), and the apex of gonocoxa 1 is lacking long black setae (present in R. ambra; comp. Figs 13 and 15). Males differ by the absence of a hairy tubercle on the protrochanter that is present in $R$. ambra, but not in $R$. madli sp. nov., and by the shape of the paramere, which is much shorter in R. ambra than in R. madli sp. nov. (comp. POLHEMUS \& ANDERSEN 2015: Figs 61, 62).

Etymology. Dedicated to our colleague Michael Madl.

\section{Rhagovelia kalalaoensis sp. nov.} (Figs 3, 6, 8, 10, 12, 14, 17)

Type material. HoLOTYPE (apterous $\hat{)}$ ) and PARATYPES ( 1 apterous $\hat{\alpha}, 1$ apterous ): Madagascar, Nosy Boraha: Forêt de Kalalao, 27.X.1992, leg. M. Madl (all NHMW).

Description. Male (apterous). Measurements (holotype, paratype): Body length 2.91, 2.55; maximum body width (at metapleura) 1.06, 1.03. Head length $0.45,0.42$, width $0.80,0.78$; minimum eye distance $0.13,0.12$. Pronotum length $0.83,0.81$, width $1.00,1.00$. Lengths of antennomeres (holotype), I 0.77, II 0.45, III 0.47, IV 0.51. Lengths of leg segments (holotype): profemur 0.94 , protibia 1.00 , protarsus $0.02+0.03+0.24$, mesofemur 1.59 , mesotibia 1.47, mesotarsus $0.10+0.50+0.72$, metafemur 1.34 , metatibia 1.44 , metatarsus $0.05+0.08+0.29$.

Colour (Fig. 3). Trunk chiefly black. Pronotum anteriorly with transverse yellow stripe medially interrupted by 
narrow blackish brown line. Tergite 6 with small yellowish brown spot, tergite 7 with large yellow spot. Laterotergites 3-6 and sternites 3-6 with narrow yellow lateral margins. Propleuron and acetabula yellow. Venter bicoloured; mesosternum until sternite 6 black, other parts yellow (segment 8 slightly darker). Antenna black, basal third of antennomere 1 yellow. Legs largely black; all coxae, proand metatrochanter, basal third of profemur, and base of metafemur yellow.

Pilosity. Body dorsally with dispersed, short, grey, appressed pubescence and inconspicuous, dispersed, grey, subdecumbent short setae; only head, sides of pronotum, and posterior margin of segment 8 with some long black setae. Tubercle of protrochanter with tuft of black setae. Profemur on posterior face with basal row of three slightly thickened setae; posterior row of flexor side with short stout setae. Other black setae on legs normal, slender, of varying length.

Structures. Jugum not flattened, narrow, with few black spicula laterally and posteriorly. Proepisternum with few black spicula anteriorly. Pronotum more than twice as long as head, covering mesonotum. Protrochanter (Fig. 6) with subapical tubercle. Profemur (Fig. 6) with distinct concavity on extensor side. Metafemur (Fig. 8) moderately incrassate, ca. 3.3-3.4 times as long as wide, on flexor side with rich dentition: basal row consisting of 13-14 densely set short spines only weakly increasing in length distally, their distance smaller than their length; posterodistal row consisting of 11-13 teeth strongly decreasing in size distally, the first one considerably longer than the second; anterodistal row consisting of 7-9 minute spines. Metatibia (Fig. 8) straight, on flexor side with fine toothlike structures along entire length, with very short apical spine. Pregenital segments of abdomen relatively slender. Tergites relatively narrow; tergites 1-5 matt, 6 with small shiny spot at middle, 7 almost entirely shiny (except margins). In holotype, fifth tergite 2.1 times as wide as long; seventh tergite 1.8 times as long as sixth and 1.0 times as long as wide. Sternites almost unmodified; sternite 7 between paired, very shallow lateral impressions very weakly convex, hind margin broadly concave. Segment 8 small, subcylindrical, with indistinct ventromedial carina.

Genital segments small and weakly modified. Pygophore slender subovate. Proctiger (Fig. 10) moderately slender, basolateral lobes moderately protruding and posteriorly angled. Paramere (Fig. 12) small, proximal part very short and setose, middle part curved, bearing short setae ventrally, distal part slightly widened and broadly rounded.

Female (apterous). The single teneral female has shrivelled during drying so that exact measurements and a description of the exact position of connexiva in a natural condition cannot be provided. However, the most important structural details allow a diagnosis of this morph:

Colour similar as in male, but sternite 7 almost entirely yellow (except margin) and yellow base of metafemur slightly smaller.

Pilosity similar to that of male, but without hair tuft on protrochanter, with slender setae on profemur, and pubescence on sternites strongly reduced. Tergites with sparse pubescence; tergite 7 (Fig. 17) with long, posteriorly directed tuft of black setae, the longest setae reaching apical third of tergite 8 . Apical tuft of setae on connexiva moderately developed. Tergite 8 , proctiger, and gonocoxa 1 with short pilosity, only the latter with a few moderately long setae.

Structural characteristics. Head and thorax similar to those of male. Protrochanter without tubercle. Metafemur more slender than in male, on flexor side with distal row consisting of 6 teeth. Metatibia without teeth on flexor side. Abdomen strongly modified. Connexiva without any swellings. The narrow posterior tergites suggest that the connexival margins are strongly convergent posteriorly in dorsal aspect. Tergites 1-3 convex, 4-8 flat; tergite 7 (Fig. 17) narrow, almost parallel-sided (weakly narrowed posteriorly), about 1.5 times as long as wide at base; tergite 8 (Fig. 17) roundish, about as wide as long and about one fourth wider than base of tergite 7 . Posterior corner of sternite 7 (Fig. 14) only slightly acute (almost rectangular) and weakly protruded.

Macropterous morphs. Unknown.

Comparative notes. Rhagovelia kalalaoensis sp. nov. is a member of the $R$. tesari group. It is very similar to $R$. aquacola Polhemus \& Andersen, 2015, but the new species is much smaller and its legs are darker. For direct comparison we used apterous specimens of $R$. aquacola originating from the type area deposited in the Natural History Museum Vienna. The two species share the armature of the legs, especially the characteristic hairy tubercle on the protrochanter of males (Fig. 6), and the long, posteriorly directed pilosity at the hind margin of tergite 7 of females (Figs 17, 18). The paramere shapes are identical. The main structural difference is found in the apterous female: in $R$. kalalaoensis sp. nov. the connexiva are slender all over their length (with strong swelling on segments 4 and 5 in R. aquacola), tergite 7 is narrower than tergite 8 (subequal in R. aquacola; comp. Figs 17 and 18), and the connexival corner of sternite 7 is less protruded in lateral aspect (comp. Figs 14 and 16). Using the key by Polmemus \& ANDERSEN (2015), R. kalalaoensis sp. nov. keys out with $R$. brincki Polhemus \& Andersen, 2015 because of its small body size, but strongly differs from it by the paramere shape and other aforementioned characters.

Etymology. Named after the type locality, the Forêt de Kalalao; adjective.

\section{Rhagovelia madari Hoberlandt, 1941}

Material examined. MADAGASCAR: Nosy BoraHA: $1 \hat{\gamma}$ (apterous), Forêt de Kalalao, 27.x.1992, leg. M. Madl; $4 \lesssim 7$ 7 우 (apterous), Forêt de Kalalao, 22.xi.1993, leg. M. Madl (NHMW).

Additional material examined. MADAGASCAR: Diego SuARez Province: $1 \hat{~(a p t e r o u s, ~ p a r a t y p e), ~ V o h e ́ m a r ~(N M P C) ; ~} 1 \hat{\jmath}$ (apterous, paratype), environment of Rogez (NMPC). Fianarantsoa Province: 11 거 5 우 (apterous), Ranomafana, 6.-10.i.1998, leg. P. Pacholátko (NHMW); 3 क 5 (apterous), Ionilahy, tributary of Ionilahy river, 21.iv.2011, leg. R. Gerecke (NHMW). Tamatave Province: 1 i 1 (apterous), environment of Moramanga, 10-18.xii.1997, leg. P. Pacholátko (NHMW).

Notes. Hoberlandt (1941) described R. madari from two localities near the north-eastern coast of Madagascar; 
the type material is deposited in the National Museum in Prague (KMEnt \& Kolínoví 2013). We compared paratype specimens from both sites with specimens from Fianarantsoa and Tamatave Provinces (NHMW) and the Nosy Boraha specimens and confirmed their conspecificity. This obviously widely distributed species belongs to the $R$. pexa group (sensu Polhemus \& ANDERSEN 2015), which needs revision.

\section{Rhagovelia reuteri Hoberlandt, 1951}

(Fig. 4)

Material examined. MADAGASCAR: Nosy BORAHA: $9 \precsim \delta 8 q q$ (macropterous), Forêt de Kalalao, 22.xi.1993, leg. M. Madl (NHMW). Additional material examined. MADAGASCAR: Fianarantsoa Province: 10 đo 12 q (apterous), Ranomafana, 6-10.i.1998, leg. P. Pacholátko (NHMW); $5 \hat{\delta} 5$ 90 (apterous), Ionilahy, tributary of Ionilahy river, 21.iv.2011, leg. R. Gerecke (NHMW); $7 \lesssim 17$ 0 우 (apterous), Ionilahy, Andahamahitsy, Manasaki River, 23.iv.2011, leg. R. Gerecke (NHMW).

Notes. Rhagovelia reuteri was described based on three specimens collected by C. Lamberton in Rogez (now called Andekaleka; fide Polhemus \& ANDERsen 2015) in the southern part of Taomasina Province. The excellent, detailed illustrations of the apterous male provided by HobERLANDT (1951) allow a safe species identification. We have also studied three large series of this species from Fianarantsoa Province for comparison (identification of one series has been confirmed by direct comparison with the holotype by the first author in the past).

The specimens from Nosy Boraha are variable in size; leg colour is slightly darker than described for the types. Small males (Fig. 4) lack the tooth at the base of the metatibia that is prominent in large males as described for the types.

\section{Rhagovelia tesari Hoberlandt, 1941}

Material examined. MADAGASCAR: Nosy BorAHA: $2 \lesssim 30 q$ (macropterous), Forêt de Kalalao, 27.x.1992, leg. M. Madl (NHMW).

Notes. Rhagovelia tesari is a rather variable species and widely distributed in the centre and north of Madagascar (PolHemus \& ANDERSEN 2015). In the distribution map of R. tesari, PolHemus \& ANDERSEn (2015: fig. 33) placed a dot which may lie either on Nosy Boraha or on the adjacent mainland, but the paper does not refer to a specimen record which corresponds with this entry.

\section{Discussion}

Our results contribute to the knowledge of endemic Rhagovelia species of Madagascar and adjacent islands which proved - now with 38 described species - to be a major centre of riffle bug diversity. It also confirms the need of protection in the various small biogeographical subregions of Madagascar.

The two species new to science are known only from Nosy Boraha. Although only wingless specimens were available for the descriptions, the occasional presence of winged individuals, which are able to disperse actively over small distances, is expected in the populations. The small distance of only $7 \mathrm{~km}$ from the mainland of Madagascar and the low elevation of the type locality raise doubts whether they could be endemic to this small island. However, the nearest suitable habitat for Rhagovelia species on mainland Madagascar lies west of Ambodimanga, more than $20 \mathrm{~km}$ away from Nosy Boraha (D. A. Polhemus, pers. comm.; see also fig. 1 in Boumans et al. 2007). This distance along with the geographic barriers present throughout the Pleistocene (Boumans et al. 2007) may increase the likelihood of species endemism.

A survey of the nearby lowlands of Madagascar may give an answer to the question of endemism. However, this land area is densely populated and mostly converted to agricultural land, so that its natural conditions have largely been destroyed. The same is now true for most parts of Nosy Boraha. The FoIBEn-TaOsarintanin'i MAdagasiKarA (1980) map still shows the Forêt de Kalalao as a continuous forest. However, already Goodman (1993), after having visited the island in 1991, reported its fragmentation and degradation. This corresponds to observations by Michael Madl in 1992 and 1993 (M. Madl, pers. comm.). Goodman (1993) concludes that the "Forêt de Kalalao has been so fragmented and reduced in size that little of it remains to be protected." A view of the present Google Earth map shows that meanwhile the area around the type locality has been fragmented to some isolated forest patches; only further south, east of Lonkintsy, a larger forest remains. Recent efforts to establish more numerous and extensive protected areas on mainland Madagascar (GARDNER et al. 2018) may yet represent a glimmer of hope that suitable habitats for the species will be conserved and may be studied to assess species endemism.

While the interpretation of insect distribution often suffers from incomplete data (e.g., ZetTel 2020), the presence of endemic species on Nosy Boraha was also discussed for vertebrates: It is not fully clear whether the extinct Delalande's coua (Coua delalandei (Temminck, 1827)), a non-parasitic cuckoo, has ever been recorded from mainland Madagascar; all properly labelled specimens originate from Nosy Boraha while undocumented observations on Madagascar may refer to related species (Goodman 1993). Nosy Boraha is also well-known for characteristic "colour forms" of reptiles. For example, the panther chameleon, Furcifer pardalis (Cuvier, 1829), shows many colour variants (see, e.g., illustrations in MüLLER et al. 2004), with a distinctive one reported from Nosy Boraha, called the "Nosy Boraha panther" among amateur herpetologists. A recent study (GRBIC et al. 2015) revealed a strong genetic structure among geographically restricted haplogroups to which male individuals can be associated by colour; however, specimens from Nosy Boraha belong to the same haplotype as specimens from the east coast of Madagascar. Although the results suggest around 9-15 species, hitherto no taxonomic changes have been made. The leaf-tailed gecko Uroplatus sameiti Böhme \& Ibisch, 1990, originally described from Nosy Boraha as a subspecies of $U$. sikorae Boettger, 1913, is a parapatric species and requires ecological parameters of the lowlands that are different from those of U. sikorae inhabiting higher altitudes (RAXWORTHY et al. 2008). However, it is not endemic to Nosy Boraha (RATSOAvina 2013), as already 
suggested in the original description (BöHME \& IBISCH 1990). In contrast to these results, a recent study on mouse lemurs (HotALING et al. 2016) describes a population from Nosy Boraha as a new species, which is chiefly based on molecular data: Microcebus boraha Hotaling et al., 2016 is treated as a distinct species although it is most closely related with $M$. simmonsi Louis et al., 2006 which inhabits the nearby lowland areas of Madagascar.

It is sad to realize that many of these local "forms" are likely to go extinct in the near future if no conservational actions are taken.

\section{Acknowledgements}

Our sincere thanks to Michael Madl (Frauenkirchen, Austria) for donation of his specimens to NHMW and for communicating the exact locality and his observations in the area; to Harald Bruckner (NHMW) for preparing the stacked images (Figs 1-4); to Petr Kment (National Museum Prague) for the loan of type specimens; and to Silke Schweiger (NHMW) for herpetological literature and advice. Comments by two reviewers, Felipe F. F. Moreira and Dan A. Polhemus, and by Petr Kment in his editorial function helped to improve the text.

\section{References}

BOUMANS L., VIEITES D. R., GLAW F. \& VENCES M. 2007: Geographical patterns of deep mitochondrial differentiation in widespread Malagasy reptiles. Molecular Phylogenetics and Evolution 45 (3): 822-839.

BÖHME W. \& IBISCH P. 1990: Studien an Uroplatus. I. Der Uroplatus-fimbriatus-Komplex. Salamandra 26 (4): 246-259.

FOIBEN-TAOSARINTANIN'I MADAGASIKARA 1980: SainteMarie, carte topographique 1:50,000. Antananarivo, Madagascar.

GARDNER C. J., NICOLL M. E., BIRKINSHAW C., HARRIS A., LEWIS R. E., RAKOTOMALALA D. \& RATSIFANDRIHAMANANA A. N. 2018: The rapid expansion of Madagascar's protected area system. Biological Conservation 220: 29-36.

GOODMAN S. M. 1993: A reconnaissance of Ile Sainte-Marie, Madagascar: the status of the forest, avifauna, lemurs and fruit bats. Biological Conservation 65 (3): 205-212.

GRBIC D., SAENKO S. V., RANDRIAMORIA T. M., DEBRY A., RASELIMANANAA. P. \& MILINKOVITCH M. C. 2015: Phylogeography and support vector machine classification of colour variation in panther chameleons. Molecular Ecology 24 (13): 3455-3466.

HOBERLANDT L. 1941: Madagaskarské ploštice v pražském muzeu. I. Veliidae. Heteroptera Madagascariensia in Museo Pragensi. I. Veliidae. Sborník Entomologického Oddělení pri Zoologických Sbirkách Zemského Musea v Praze 19: 67-75, 1 pl.

HOBERLANDT L. 1951: Madagascan species of Rhagovelia. Societas Scientiarum Fennica, Commentationes Biologicae 12 (5): 1-12.
HOTALING S., FOLEY M. E., LAWRENCE N. M., BOCANEGRA J., BLANCO M. B., RASOLOARISON R., KAPPELER P. M., BARRETT M. A., YODER A. D. \& WEISROCK D. W. 2016: Species discovery and validation in a cryptic radiation of endangered primates: coalescent-based species delimitation in Madagascar's mouse lemurs. Molecular Ecology 25(9): 2029-2045.

KMENT P. \& KOLÍNOVÁ Z. 2013: Catalogue of type specimens of true bugs (Hemiptera: Heteroptera) deposited in the National Museum, Prague, Czech Republic. Enicocephalomorpha, Dipsocoromorpha, Nepomorpha, Gerromorpha, and Leptopodomorpha. Acta Entomologica Musei Nationalis Pragae 53 (2): 821-890.

LUNDBLAD O. 1936: Die altweltlichen Arten der Veliidengattungen Rhagovelia und Tetraripis. Arkiv för Zoologi 28A (21): 1-63 + tab. $1-13$.

MÜLLER R., LUTZMANN N. \& WALBRÖL U. 2004. Furcifer pardalis - Das Pantherchamäleon. Natur und Tier Verlag, Münster, 127 pp.

NIESER N., ZETTEL H. \& CHEN P.-p. 1997: Ten new species of Rhagovelia (Heteroptera: Veliidae) from Sulawesi (Indonesia). Tijdschrift voor Entomologie 140: 17-41.

POISSON R. 1945: Quelques hémiptères aquatiques africains et malgaches. Bulletin de la Société Entomologique de France 50: 87-94.

POISSON R. 1948: Contribution a l'étude des Hydrocorises de Madagascar (Mission J. Millot 1946). Memoires de l'Institut Scientifique de Madagascar (A) 1 (2): 89-120.

POISSON R. 1951: Contribution a l'étude des Hydrocorises de Madagascar (Mission J. Millot 1947-1948). $2^{\mathrm{e}}$ note. Memoires de l'Institut Scientifique de Madagascar (A) 5: 79-130.

POISSON R. 1952: Contribution a l'étude des Hydrocorises de Madagascar (Mission J. Millot et R. Paulian, 1949). $3^{\mathrm{e}}$ note. Memoires de l'Institut Scientifique de Madagascar (E) 1 (1): 23-70.

POLHEMUS D. A. \& ANDERSEN N. M. 2010: Rhagovelia of Madagascar and nearby Indian Ocean Islands (Hemiptera: Veliidae). Revision of the diabolica species group. Insect Systematics and Evolution 41: 143-186.

POLHEMUS D. A. \& ANDERSEN N. M. 2015: Rhagovelia of Madagascar and nearby Indian Ocean Islands (Hemiptera: Veliidae), Part 2: Revision of the tesari species group. Insect Systematics and Evolution 46: 115-220.

RATSOAVINA F. M., RAMINOSOA N. R., LOUIS E. E. JR., RASELIMANANAA. P., GLAW F. \& VENCES M. 2013: An overview of Madagascar's leaf tailed geckos (genus Uroplatus): species boundaries, candidate species and review of geographical distribution based on molecular data. Salamandra 49 (3): 115-148.

RAXWORTHY C. J., PEARSON R. G., ZIMKUS B. M., REDDY S., DEO A. J., NUSSBAUM R. A. \& INGRAM C. M., 2008: Continental speciation in the tropics: contrasting biogeographic patterns of divergence in the Uroplatus leaf-tailed gecko radiation of Madagascar. Journal of Zoology 275: 423-440.

ZETTEL H. 1996: Revision der philippinischen Arten der Gattung Rhagovelia, 3. Teil (Heteroptera: Veliidae). Entomological Problems 27 (2): 111-140.

ZETTEL H. 2012: Neue Veliidae (Hemiptera: Heteroptera) von den Philippinen. Zeitschrift der Arbeitsgemeinschaft Österreichischer Entomologen 64: 79-118.

ZETTEL H. 2020: New water strider species of Eurymetra from Madagascar (Hemiptera: Heteroptera: Gerridae). Acta Entomologica Musei Nationalis Pragae 60 (1): 15-22. 
